\title{
Obesity and overweight in Bangladeshi children and adolescents: a scoping review
}

\author{
Sholeh Rahman ${ }^{\dagger}$, Md Tauhidul Islam ${ }^{\dagger}$ and Dewan S Alam
}

\begin{abstract}
Background: Obesity and overweight in children and adolescents is an emerging public health concern alongside under-nutrition in low and middle income countries. Our aim was to conduct a scoping review of literature to ascertain what is known about childhood and adolescent overweight and/or obesity in Bangladesh.

Method: Using the scoping review based on York methodology, a comprehensive search of published academic articles, conference proceedings and grey literature was carried out through PubMed, BanglaJOL, Google and Google scholar limited to English-written papers. We summarized prevalence, risk factors and health outcomes of obesity/overweight in young children and adolescents aged between 0 to 19 years old in Bangladesh and highlighted use of different reference standards to measure childhood obesity.

Results: In total 21 studies met the inclusion criteria. Nearly all of the reviewed articles used data from cross sectional studies, while only two used case-control design. Overall thirteen studies (62\%) were primary research and eight (38\%) included secondary data. Studies indicated an increasing trend in childhood obesity over time. Prevalence ranged from less than $1 \%$ to $17.9 \%$ based on different reference standards, with higher percentage amongst urban children across different age groups and sexes.

Conclusion: This review demonstrated paucity of comprehensive literature on childhood obesity in Bangladesh, which might be explored through population-based prospective studies based on strong methodology and uniform reference standards. Sustainable and scalable preventative measures targeting high risk groups are required to avoid further rise.
\end{abstract}

Keywords: Overweight, Obesity, Children, Adolescents, Prevalence, Bangladesh

\section{Background}

Obesity in children and adolescents is rising alarmingly and approaching epidemic proportion in many economically developed countries, particularly in USA, Canada, Australia and several European countries [1]. Likewise in developing countries this issue is emerging as a public health crisis. According to a recent report, out of an estimated 43 million obese children worldwide in 2010, approximately $81 \%$ were from developing countries, half of which (18 million) were reported to be living in Asia despite of huge burden of under-nutrition. By 2020, it is estimated that the global prevalence of childhood obesity will reach approximately 60 million [2].

\footnotetext{
* Correspondence: dsalam@icddrb.org

${ }^{\dagger}$ Equal contributors

Centre for Control of Chronic Diseases (CCCD), icddr,b, 68 Shaheed Tajuddin Ahmed Sharani, Mohakhali Dhaka 1212, Bangladesh
}

Factors contributing to the rising levels of childhood obesity in developing countries include socio-economic development, changes in lifestyle characterized by physical inactivity and unhealthy diet, living patterns, as well as rapid epidemiological and demographic transition $[3,4]$.

WHO (2013) considers childhood obesity as "one of the most serious public health challenges of $21^{\text {st }}$ century" [5]. It accounts for a wide range of psychosocial and medical consequences [6]. Lower self-esteem, social isolation, poor academic achievement and peer problems are the most apparent immediate consequences in obese children [7]. Obesity in children and adolescents predisposes them to and is causally linked with cardio-metabolic disorders such as hypertension, dyslipidaemia and insulin resistance which are well-established illnesses [8]. As overweight and obesity is likely to follow through into adulthood, in the longer term, there is a greater risk of developing 
cardiovascular diseases $[9,10]$. Obesity at a young age seems to have substantial impact on reducing life expectancy [11]. Evidence also suggests a link between obesity in young girls with potential menstrual disorders, hypertension in pregnancy and sub-fertility [12].

In Bangladesh, the context of obesity and overweight has been underexplored, more so amongst younger age groups. Understanding the current situation and trends will provide useful insights into its risk factors and will assist health professionals and policy-makers in decisionmaking and developing future research agenda. This paper explored the availability of literature on childhood and adolescent obesity/overweight and its determinants in Bangladesh through a scoping review which, unlike a systematic review, offers a much broader perspective in the respective field which makes it more appropriate method to assess the present situation of childhood and adolescent obesity in Bangladesh [13].

\section{Methods}

A scoping review was performed based on the York methodology outlined by Arksey and O' Malley from the University of York, United Kingdom [13]. The 'York framework' suggested five stages that we have followed for this review:

Stage 1: Identifying the research question

Stage 2: Identifying the relevant studies

Stage 3: Study selection

Stage 4: Charting the data

Stage 5: Collating, summarizing and reporting the results

Initially, we defined research questions and developed search strategy and discussed them in a team meeting. Relevant literatures were then identified through a comprehensive search across different databases including Pubmed, Google, Google scholar and Bangladesh's country specific search engine (BanglaJOL). We used specific key words that included obesity, overweight, adiposity, BMI, childhood, adolescents and Bangladesh. Search terms were combined using Boolean operators (AND, OR, NOT) to narrow the results [14]. In addition, hand searching of appropriate reference lists were undertaken to identify any additional literatures or grey publications. Figure 1 shows different steps of the review conducted.

\section{Selection of literature}

We included the publication if:

- obesity and/or overweight was its primary or secondary outcome or an associated risk factor;

- study participants were Bangladeshi children and adolescents aged between 0 to 19 year old;

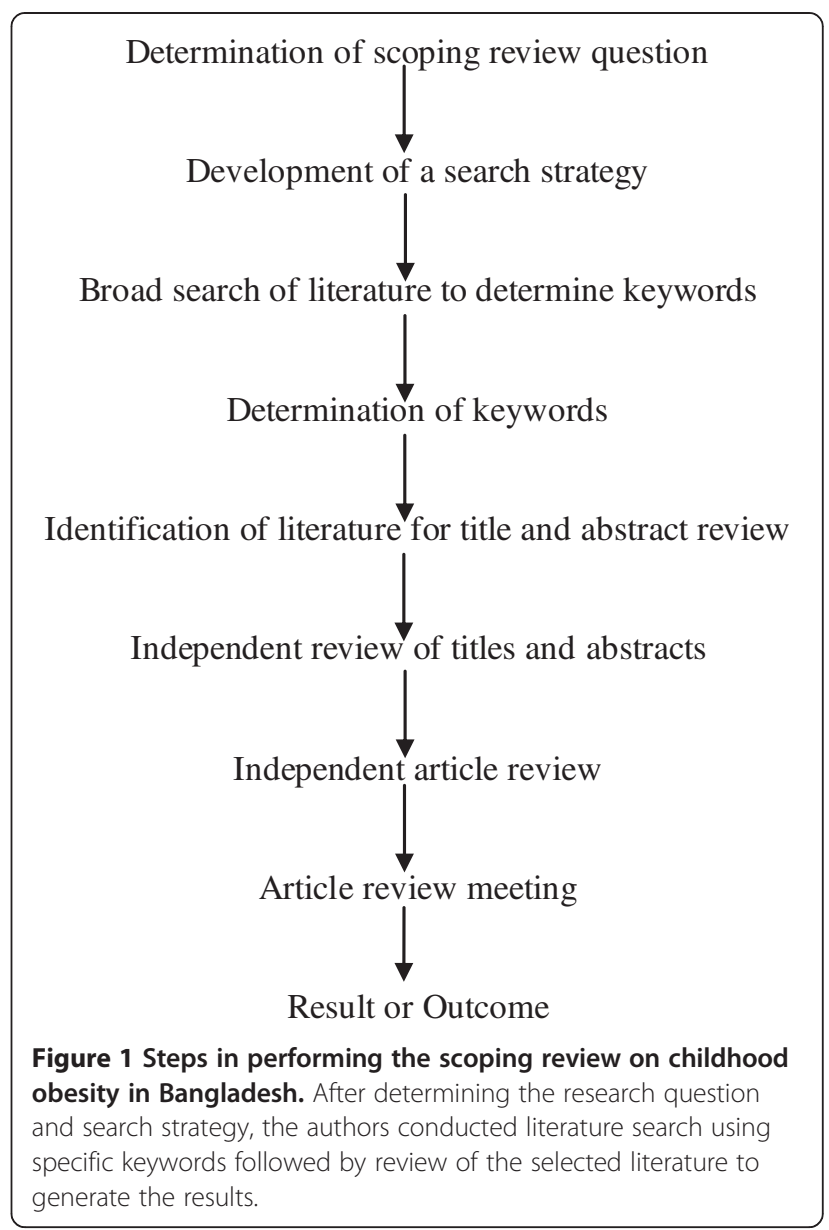

- it was relevant to any aspect of obesity, such as its prevalence, determinants, nutrition and growth in children and adolescents, anthropometry and health status; and

- it was written in English; no other limits on publication date of the articles were considered.

Papers were excluded if the study sample was older than 19 years of age or resided in countries other than Bangladesh. The initial search of databases revealed 241 literatures of which 159 were excluded after screening their titles and abstracts. One paper was not available even after contacting the library services and the publisher. The remaining 82 papers were screened for relevancy of their objectives, out of which a further 39 papers were excluded due to duplication or overlapping. Full copies of 43 literatures were read first independently and then reviewed again by the authors, which resulted in further exclusion of 35 papers as they did not meet our inclusion criteria. We retrieved 14 papers through manual search, from which one was excluded because of its apparently unrealistic results as well as lack of access to the full article [15]. The final number of papers 
included in this review narrowed down to 21, constituting of 19 full papers, 1 journal abstract and 1 conference proceeding [16-36] (Figure 2). Details of each of the included papers were then summarized (Table 1).

\section{Results}

Application of inclusion and exclusion criteria resulted in overall selection of 21 papers for this review; searching BanglaJOL, PubMed, Google and Google Scholar revealed 1,7 and 13 relevant papers respectively. Literatures selected were from a 15 year period with the oldest from 1998 to the most recent in 2013. The search did not retrieve any relevant literature beyond these dates.

\section{Characteristics of the selected data}

Seventy one percent of the studies $(n=15)$ included participants from both sexes and $29 \%$ involved females only $(n=6)$. Age range of the participants varied considerably across different studies. To make the interpretation easier, we decided to divide the studies into three categories according to their participants' age range: group A (included those 5 years of age or younger), group B (included those over 5 years of age), group $C$ (mixed group included subjects younger and older than 5 years of age). Accordingly twelve studies that examined obesity fell in group B, five in group $\mathrm{A}$ and only four in group $\mathrm{C}$ which included both age categories. In terms of the study site, majority of the studies $(n=14)$ were conducted in urban setting, six studies examined obesity in both urban and rural, and only one paper reported obesity in rural setting.

\section{Study design, measurement and reference standards}

Sixty two percent $(n=13)$ of the studies were primary research and thirty eight percent $(n=8)$ used secondary data for their result synthesis. Bangladesh Demographic and Health Survey (BDHS 2004 and 2007), Nutrition Surveillance Project (NSP 2000-2004), WHO database (1996) and Diarrheal Disease Surveillance System (DDSS

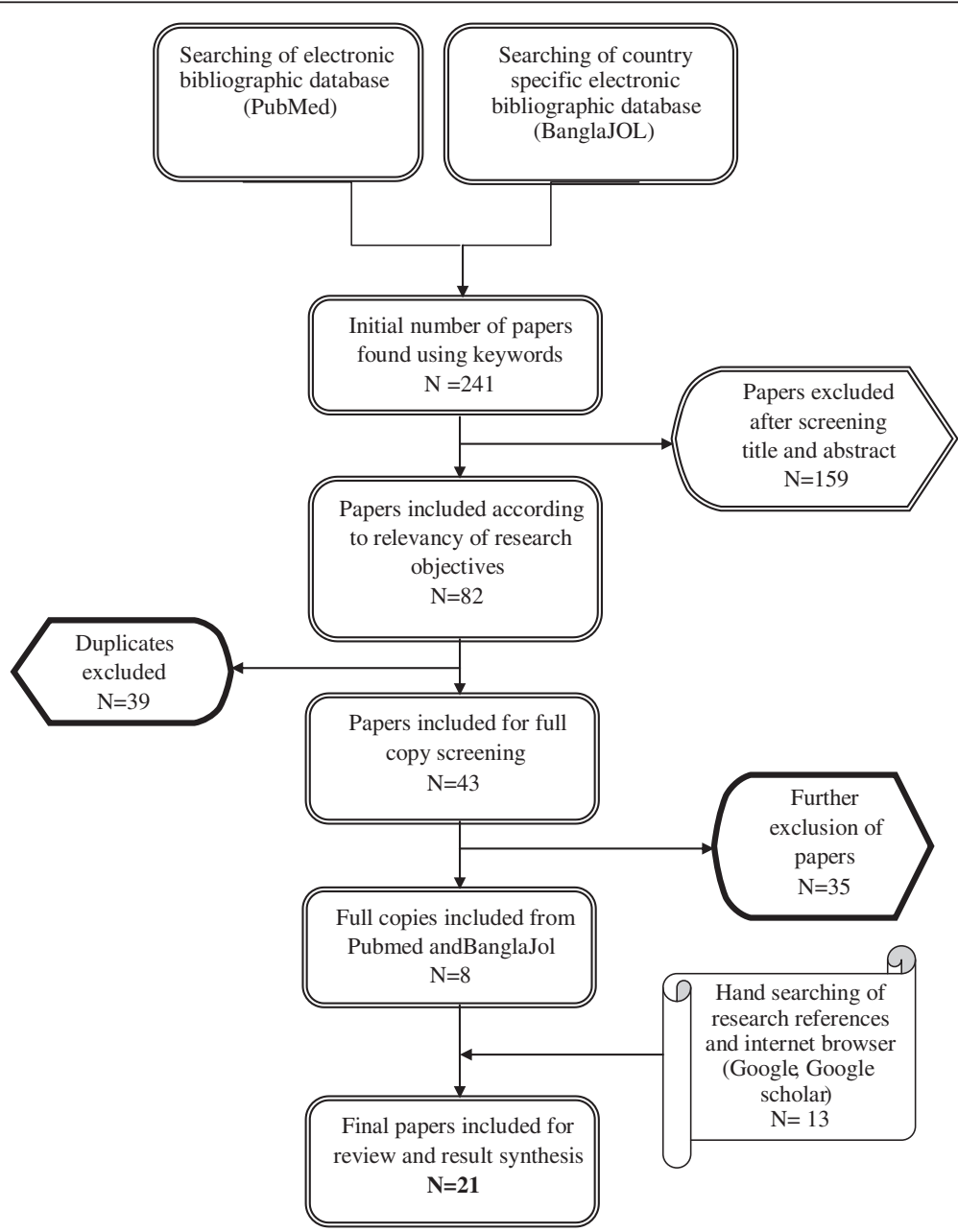

Figure 2 Flowchart of the number of literature searched and selected. Sequential steps undertaken for final inclusion of the literature in our review. 
Table 1 Studies of childhood and adolescent obesity included in the review by study design, sample size, anthropometric indices and reference standards

\begin{tabular}{|c|c|c|c|c|}
\hline Author(s) and year & $\mathrm{n}$ & Study design & Anthropometric index & Reference standard \\
\hline Das et al., 2013 [16] & 33,482 & Cross-sectional & $\begin{array}{l}\text { Weight for age (under } 5) \text { \& BMI } \\
\quad \text { for age (5-19 years) }\end{array}$ & $\begin{array}{c}\text { WHO, } 2009^{1} \text { National Obesity } \\
\text { Observatory, } 2011^{2}\end{array}$ \\
\hline Bhuiyan, 2013 [17] & 198 & Case-Control & BMl & $C D C, 2000^{3}$ \\
\hline $\begin{array}{l}\text { Hossain et al., } \\
2012[18]\end{array}$ & $10,115^{*}$ & Cross-sectional & BMI & WHO, $2006^{4}$ \\
\hline $\begin{array}{l}\text { Mohsin et al., } \\
2012 \text { [19] }\end{array}$ & 161 & Cross-sectional & $\mathrm{BMI}$ & $C D C, 2000^{3}$ \\
\hline $\begin{array}{l}\text { Saha et al., } \\
\text { 2011-2012 [20] }\end{array}$ & 96 & Cross-sectional & Not defined & N/A \\
\hline Corsi et al., 2011 [21] & 1439 & Cross-sectional & BMl & WHO, $2004^{5}$ \\
\hline $\begin{array}{l}\text { Jesmin et al., } \\
2011[22]\end{array}$ & 380 & Cross-sectional & Weight for height & WHO, $2006^{4}$ \\
\hline $\begin{array}{l}\text { Mohsin et al., } \\
2011 \text { [23] }\end{array}$ & 161 & Cross-sectional & $\mathrm{BMI}$ & $C D C, 2000^{3}$ \\
\hline $\begin{array}{l}\text { Mohsin et al., } \\
2010[24]\end{array}$ & 468 & Cross-sectional & $\mathrm{BMI}$ & $C D C, 2000^{3}$ \\
\hline Sultana, $2010[25]$ & 1200 & Cross-sectional & Weight for height & $\mathrm{WHO}, 1995^{6}$ \\
\hline $\begin{array}{l}\text { Kurshed et al., } \\
2010[26]\end{array}$ & 352 & Cross-sectional & BMl & WHO, $1995^{6}$ \\
\hline $\begin{array}{l}\text { Rahman et al., } \\
2009[27]\end{array}$ & 652 & Cross-sectional & BMI & $C D C, 2000^{3}$ \\
\hline $\begin{array}{l}\text { Balarajan et al., } \\
2009 \text { [28] }\end{array}$ & 1328 & Cross-sectional & BMI & $\mathrm{WHO}, 1995^{6}$ \\
\hline $\begin{array}{l}\text { Khan et al., } \\
2009[29]\end{array}$ & 425 & Cross-sectional & BMI & $\mathrm{WHO}, 2004^{5}$ \\
\hline $\begin{array}{l}\text { Sultan et al., } \\
2008[30]\end{array}$ & 172 & Cross-sectional & BMI & Dietz \& Robinson, $1998^{7}$ \\
\hline $\begin{array}{l}\text { Shafique et al., } \\
2007 \text { [31] }\end{array}$ & 16404 & Cross-sectional & $\mathrm{BMI}$ & $\mathrm{WHO}, 2004^{5}$ \\
\hline $\begin{array}{l}\text { BBS/UNICEF, } \\
2007[32]\end{array}$ & 3797 & Cross-sectional & BMl & WHO, $1995^{6}$ \\
\hline $\begin{array}{l}\text { Rahman et al., } \\
2002 \text { [33] }\end{array}$ & 5000 & $\begin{array}{l}\text { Case control preceded by } \\
\text { cross-sectional survey }\end{array}$ & Weight for Height & Not mentioned \\
\hline de Onis et al., 2000 [34] & 4787 & Cross-sectional & Weight for Height & $\mathrm{WHO}, 1995^{6}$ \\
\hline $\begin{array}{l}\text { Rahman et al., } \\
1998 \text { [35] }\end{array}$ & 316 & Cross-sectional & Weight for Height & WHO, $1993^{8}$ \\
\hline $\begin{array}{l}\text { Ferdousi et.al., } \\
2011[36]\end{array}$ & 202 & Cross-sectional & $\mathrm{BMI}$ & $\mathrm{WHO}, 2004^{5}$ \\
\hline
\end{tabular}

${ }^{1}$ WHO Growth Standards for Infants and Young Children.

${ }^{2}$ A Simple Guide to Classifying Body Mass Index in Children, Public Health Observatories, England.

${ }^{3} 2000$ CDC Growth Charts for the United States: Methods and development.

${ }^{4}$ WHO Child Growth Standards.

${ }^{5}$ Appropriate body-mass index for Asian populations and its implications for policy and intervention strategies, report of a WHO expert committee.

${ }^{6}$ Physical status: the use and interpretation of anthropometry, report of a WHO expert committee.

${ }^{7}$ Use of body mass index as a measure of overweight in children and adolescents.

${ }^{8}$ Measuring changes in nutritional status.

*Overall sample size included women aged between 15 to 49 years, but sample size for the adolescent group was not mentioned.

1993-2011) were used as the sources of secondary data. The design of the selected studies was mostly crosssectional, except for two studies which employed casecontrol design. Amongst the case control studies, one study was preceded by a cross-sectional survey. Different standards were used for defining overweight and obesity across the studies (Table 1). BMI cut-off value was used as a measure of overweight/obesity in $62 \%(n=13)$ of the studies reviewed, including three studies in under 5 year age group. The remaining 28\% $(n=6)$ adopted 
weight for height as an index of body size. Only one study did not mention the body size measurement index [20]. Another study used weight-for-age amongst children who were under 5 years of age and BMI-for-age amongst 5-19 years old [16]. No direct body composition based measure of adiposity was used in any of the reviewed articles. WHO standard for obesity and overweight has been changed and modified over time; however, it was the most commonly used reference for cut-off values in the studies. Few studies used CDC growth chart as their reference standard.

\section{Prevalence of obesity, associated factors and health outcome}

Prevalence of overweight and/or obesity was reported in seventeen of the studies and it was the primary outcome in eight of them (47\%). The rest of the studies addressed obesity as their secondary outcome. Since the studies did not use the same reference standards, the prevalence of overweight and obesity could not be compared across the studies. However, the reported prevalence varied widely and has been summarized according to the age groups and presented in Table 2. Recent survey by Bangladesh Bureau of Statistics (BBS) and UNICEF has reported 1.4\% prevalence of overweight amongst children less than 5 years of age [32]. A study conducted amongst school children in Dhaka aged between 3 to 18 years of age, found $17.9 \%$ obese and $23.6 \%$ overweight children and adolescents [24]. In another study, the prevalence of obesity was found to be $13 \%$ and that of overweight was $11.5 \%$ amongst urban children aged between 2 to 10 years old; and obesity showed an increase with higher family income [35]. Most recent study (2013) among urban children, reported approximately a five fold increase in overweight and obesity over the past two decades [16]. In addition, two unpublished studies reported $17.8 \%$ and $7.6 \%$ obesity in children of different age categories [25,33]; obesity was significantly more in the highest income group $(\mathrm{OR}=2.06)$ [25].

Only two studies assessed metabolic syndrome in children and adolescents. One of them reported metabolic syndrome in more than $36 \%$ of obese children and adolescents with greater number amongst girls [23]. Another one reported 17\% IGT, 2\% Diabetes Mellitus and 26\% high

Table 2 Prevalence (\%) of obesity and overweight amongst children and adolescents by sex, age range and setting of the study

\begin{tabular}{|c|c|c|c|c|c|}
\hline & Author(s) and year & Age range & Settings & Sex & Prevalence of overweight/obesity \\
\hline \multirow[t]{7}{*}{ Group A } & Jesmin et al., 2011 & 0-59 months & Urban & Both & Obesity: $3.9 \%$ \\
\hline & Rahman et al., 2009 & 24-59 months & Rural & Both & At risk of overweight- male: $0.3 \%$, female: $0.6 \%$ \\
\hline & & & & & Overweight- male: $1.1 \%$, female: $0.6 \%$ \\
\hline & Sultan et al., 2008 & 1-12 months & Urban & Both & Obesity: 14\%; Overweight: $25.6 \%$ \\
\hline & BBS/UNICEF, 2007 & 0-59 months & Rural and urban & Both & Overweight/Obesity $1.4 \%$ (male: $1.2 \%$, female: $1.6 \%$ ) \\
\hline & & & & & Severe overweight/obesity: $0.3 \%$ \\
\hline & de Onis et al., 2000 & $<5$ years & Rural and urban & Both & Overweight: 1.1\% \\
\hline \multirow[t]{8}{*}{ Group B } & Hossain et al., 2012 & $15-19$ years $^{1}$ & Rural and urban & Females only & Obesity: less than $1 \%$ \\
\hline & Corsi et al., 2011 & $15-19$ years $^{1}$ & Rural and urban & Females only & Overweight: 1.6\% \\
\hline & Kurshed et al., 2010 & $10-18$ years & Urban & Females only & Overweight/obesity: $4.6 \%$ \\
\hline & Sultana, 2010 & $6-13$ years & Urban & Both & Overweight: 13.2\%; Obesity: 17.8\% \\
\hline & Khan et al., 2009 & $13-19$ years $^{2}$ & Urban & Females only & Overweight: $2.1 \%$; Obesity: $0.9 \%$ \\
\hline & Balarajan et al., 2009 & $15-18$ years $^{1}$ & Urban & Females only & Overweight/obesity: $1.8 \%$ \\
\hline & Shafique et al., 2007 & $15-18$ years $^{1}$ & Rural and urban & Females only & Zero prevalence of overweight or obesity \\
\hline & Ferdousi et al., 2011 & $6-10$ years & Urban & Both & Overweight: $18.32 \%$ and higher among males (10.9\%) \\
\hline \multirow[t]{5}{*}{ Group C } & Mohsin et al., 2010 & $3-18$ years & Urban & Both & Overweight: 23.6\%; Obesity: 17.9\% \\
\hline & Rahman et al., 2002 & $2-10$ years & Urban & Both & Obesity: $7.6 \%$ \\
\hline & Rahman et al., 1998 & $2-10$ years & Urban & Both & Overweight: 11.5\%; Obesity: 13\% \\
\hline & Das et al., 2013 & $<5$ years $^{3}$ & Urban & Both & Overweight \& obesity in < 5: 5.15\% \\
\hline & & $5-19$ years & & & Overweight \& obesity in $5-19$ years: $6.7 \%$ \\
\hline
\end{tabular}

Group A: $\leq 5$ years of age.

Group B: $>5$ years of age.

Group C: Mixed group including subjects younger and older than 5 years of age.

${ }^{1}$ Age range in overall sample was between 15 to 49 years.

${ }^{2} \mathrm{Age}$ range of overall sample was between 13 to 49 years.

${ }^{3}$ Overall sample also included $>19$ years adults. 
total cholesterol among obese children and adolescents [19]. Majority of the studies $(n=14)$ assessed determinants and associated risk factors of obesity. Overall higher socio-economic status, parents higher education (maternal), higher rank occupation, parental obesity, urban residence and physical inactivity were found to be positively associated with overweight and obesity. One study suggested that vitamin A supplements $(\mathrm{OR}=1.665)$ and mother's higher education $(\mathrm{OR}=1.98)$ were positively associated with healthy, non-obese children [27].

\section{Discussion}

Obesity has been studied extensively in many developed countries, but in Bangladesh studies and data related to obesity in children and adolescents are relatively scarce. To our knowledge, this study is the first and only scoping review that has been conducted on the topic in Bangladesh which has employed a comprehensive search of published and un-published literature.

In our review, it was found that the prevalence of overweight and obesity varies significantly across the studies. However, lack of a uniform definition and reference standard makes it difficult to compare the data across studies and predict the trends accurately. We observed greater data scarcity from rural settings than urban, as majority of the studies represented urban children. Although, socioeconomic stratification had not been defined in most of the studies, overall greater prevalence of obesity and overweight was reported amongst urban children and adolescents compared to those from rural backgrounds which clearly suggest socio-economic and lifestyle differences in two different settings. In one study overweight and obesity was stated as high as $23.6 \%$ and $17.9 \%$ respectively amongst affluent urban children [24]. On the other hand, less than $2 \%$ of rural children had been reported as being overweight [27]. These findings are in line with similar studies from neighboring India and Thailand which reported greater prevalence of obesity amongst urban children than rural ones $[37,38]$.

Substantial amount of evidence is available on the occurrence of metabolic syndrome in obese children and adolescents. Several studies have reported an association between obesity with a wide range of complications in childhood as well as an increased likelihood of premature onset of chronic illnesses in later life [39-42]. Evidences show simultaneous rise in the prevalence of diabetes and overweight in children, which suggests their close inter-relationship [43-45]. However, little is known in this regard in developing countries, due to limited number of studies. In our review too, we came across very few studies which estimated the prevalence of metabolic syndrome in relation to childhood obesity [19,23], which made it difficult to predict an association between the two. More than half of the studies included in our review assessed the risk factors of childhood obesity/ overweight, irrespective of their design. A positive association between obesity with higher socio-economic status, lack of physical activity and urban residence has been reported. These findings are in accordance with studies from other developing countries which identified the similar risk factors [46,47]. In terms of maternal education, findings were contradictory; one study reported a positive association between child obesity and higher maternal education [16], while another one reported no association [17]. Overall, in our country there is a knowledge gap regarding other risk factors of obesity such as gender, birth weight and socio-cultural factors.

Our review has some limitations. Unlike a systematic review, we did not assess the quality of the studies included in our review, therefore, there is a possibility that the prevalence of overweight and/or obesity might have been exaggerated or underestimated as a result of methodological constraints. The reference standards that have been used in the studies reviewed have not been consistent. Some information might be missing due to inaccessibility of certain databases. In addition, there might have been other unpublished studies that are not available online which could not be revealed. Moreover, information on certain groups, such as tribal or ethnic minorities, is missing. Nevertheless, the findings of this review provide useful insights for future research needs in this area.

\section{Conclusion}

This review demonstrated that there is a noticeable published literature gap regarding child and adolescence obesity/overweight in Bangladesh. Although, in general, young age obesity is not considered as a major public health problem in Bangladesh yet, it is alarmingly high and on rise amongst certain groups, particularly amongst urban children from affluent households. Addressing the problem at its earliest could be achieved through identifying high risk groups and designing sustainable interventions which could be implemented on a larger scale to prevent further rise in overweight and obesity. In addition, determining the prevalence of metabolic syndrome amongst them might play a vital role in preventing socio-economic and public health burden in later life.

Implementing school-based programs that could be expanded to population level to promote physical activity and healthy food habits could have a potential impact. Furthermore, large scale prospective studies based on context-specific definition and reference standards of obesity in South-Asian population are required to enhance data comparability and prediction of future trends.

Competing interests

The authors declare that they have no competing interests. 


\section{Authors' contributions}

SR, MTI and DSA contributed equally to reviewing the literature, interpreting the results, writing the final report and they are responsible for the final content of this paper. All authors read and approved the final manuscript.

\section{Acknowledgments}

This study was supported by icddr,b. icddr,b acknowledges with gratitude the commitment of the Centre's donors for their generous support to its research efforts. The content of this paper is solely the responsibility of the authors and does not necessarily represent the official view of their employing institution.

Received: 10 September 2013 Accepted: 13 January 2014 Published: 22 January 2014

\section{References}

1. Wang Y, Lobstein T: Worldwide trends in childhood overweight and obesity. Pediatr Obes 2006, 1(1):11-25. doi:10.1080/17477160600586747.

2. de Onis M, Blossner M, Borghi E: Global prevalence and trends of overweight and obesity among preschool children. Am J Clin Nutr 2010, 92(5):1257-1264. doi:10.3945/ajcn.2010.29786.

3. Popkin BM: An overview on the nutrition transition and its health implications: The Bellagio meeting. Public Health Nutr 2002, 5(1A):93-103. doi:10.1079/PHN2001280

4. Davison KK, Birch LL: Childhood overweight: a contextual model and recommendations for future research. Obes Rev 2001, 2(3):159-171. doi:10.1046/j.1467-789x.2001.00036.x.

5. World Health Organization: Childhood overweight and obesity on the rise: Global Strategy on Diet, Physical Activity and Health. 2004. http://www.who. int/dietphysicalactivity/childhood/en/

6. Lee YS: Consequences of childhood obesity. Ann Acad Med Singapore 2009, 38(1):75-77.

7. Dietz WH: Health consequences of obesity in youth: childhood predictors of adult disease. Am Acad Pediatrics 1998, 101(Suppl 2):518-525.

8. Reilly JJ: Descriptive epidemiology and health consequences of childhood obesity. Best Pract Res Clin Endocrinol Metab 2005, 19(3):327-341. doi:10.1016/j.beem.2005.04.002

9. Baker JL, Olsen LW, Sorensen TIA: Childhood body-mass index and the risk of coronary heart disease in adulthood. N Engl J Med 2007, 357(23):2329-2337. doi:10.1056/NEJMoa072515.

10. Gunnell DJ, Frankel SJ, Nanchahal K, Peters TJ, Smith GD: Childhood obesity and adult cardiovascular mortality: a 57-y follow-up study based on the Boyd Orr cohort. Am J Clin Nutr 1998, 67(6):1111-1118

11. St-Onge MP, Heymsfield SB: Overweight and obesity status are linked to lower life expectancy. Nutr Rev 2003, 61(9):313-316. doi:10.1301/nr.2003. sept.313-316.

12. Lake JK, Power C, Cole TJ: Women's reproductive health: the role of body mass index in early and adult life. Int J Obes Relat Metab Disord 1997 21(6):432-438. doi:10.1038/sj.ijo.0800424

13. Arksey H, O'Malley L: Scoping studies: towards a methodological framework. Int J Soc Res Methodo/ 2005, 8(1):19-32. doi:10.1080/ 1364557032000119616

14. MIT Libraries: Database Search Tips: Boolean operators. http://libguides.mit. edu/content.php?pid=36863\&sid=271372.

15. Ahmed S, Karim R: Socioeconomic differentials of childhood obesity among school children of affluent society in Dhaka city. J Paediatr Child Health 2010, 46(2):17-23. doi:10.1111/j.1440-1754.2010.01723.x (abstr).

16. Das SK, Chisti MJ, Huq S, Malek MA, Vanderlee L, Salam MA, Ahmed T, Faruque ASG, Al Mamun A: Changing trend of overweight and obesity and their associated factors in an urban population of Bangladesh. Food Nutr 2013, 4:678-689. doi:10.4236/fns.2013.46087.

17. Bhuiyan MU, Zaman S, Ahmed T: Risk factors associated with overweight and obesity among urban school children and adolescents in Bangladesh: a case-control study. BMC Pediatr 2013 13(1):72. doi:10.1186/1471-2431-13-72.

18. Hossain MG, Bharati $P$, Aik SAW, Lestrel PE, Abeer A, Kamarul T, Aekplakorn W, Mo-Suwan L, Al-Isa AN, Bendixen H: Body mass index of married Bangladeshi women: trends and association with sociodemographic factors. J Biosoc Sci 2012, 44(4):385. doi:10.1017/ S002193201200003X
19. Mohsin F, Mahbuba S, Begum T, Azad K, Nahar N: Prevalence of impaired glucose tolerance among children and adolescents with obesity. Mymensingh Med J 2012, 21(4):684-690.

20. Saha S, Zahid MK, Rasheed S: The Study of the level of knowledge, attitude, practices (KAP) as well as the effects of school environment on the nutritional status of children (7-12) coming from affluent families in the Dhaka city in Bangladesh. J Nutr 2011-2012, 24-25:31-48. doi:10.3329/ bjnut.v24i0.14035.

21. Corsi DJ, Kyu HH, Subramanian SV: Socioeconomic and geographic patterning of under-and overnutrition among women in Bangladesh. J Nutr 2011, 141(4):631-638. doi:10.3945/jn.110.131599.

22. Jesmin A, Yamamoto SS, Malik AA, Haque MA: Prevalence and determinants of chronic malnutrition among preschool children: a cross-sectional study in Dhaka City, Bangladesh. J Health Popul Nutr 2011, 29(5):494-499.

23. Mohsin F, Baki A, Nahar J, Akhtar S, Begum T, Azad K, Nahar N: Prevalence of metabolic syndrome among obese children and adolescents. Birdem Med J 2011, 1(1):21-25. doi:10.3329/birdem.v1i1.12382.

24. Mohsin F, Tayyeb S, Baki A, Sarker S, Zabeen B, Begum T, Azad K, Nahar N: Prevalence of obesity among affluent school children in Dhaka. Mymensingh Med J 2010, 19(4):549-554.

25. Sultana S: Prevalence and risk factor of childhood overweight and obesity in primary school children of Dhaka city, Master thesis. University of Oslo: Faculty of Medicine; 2010. http://urn.nb.no/URN:NBN:no-26615.

26. Kurshed AAM, Rana MM, Khan S, Azad TMA, Begum J, Bhuyan MAH: Dietary intake, physical activities and nutritional status of adolescent girls in an urban population of Bangladesh. Ibrahim Medical College Journal 2010, 4(2):78-82. doi:10.3329/imcj.v4i2.6502.

27. Rahman M, Mostofa G, Nasrin SO: Nutritional status among children aged 24-59 months in rural Bangladesh: an assessment measured by BMI index. In Internet Journal of Biological Anthropology. Volume 3. Texas: Internet Scientific Publications LLC; 2009.

28. Balarajan $Y$, Villamor E: Nationally representative surveys show recent increases in the prevalence of overweight and obesity among women of reproductive age in Bangladesh, Nepal, and India. J Nutr 2009, 139(11):2139-2144. doi:10.3945/jn.109.112029.

29. Khan MMH, Kraemer A: Factors associated with being underweight, overweight and obese among ever-married non-pregnant urban women in Bangladesh. Singapore Med J 2009, 50(8):804-813.

30. Sultan K, Habiba T: Prevalence of overweight and obesity in infancy. Bangladesh Med Res Counc Bull 2008, 34(2):69-70. doi:10.3329/bmrcb. v34i2.1180.

31. Shafique S, Akhter N, Stallkamp G, de Pee S, Panagides D, Bloem MW: Trends of under-and overweight among rural and urban poor women indicate the double burden of malnutrition in Bangladesh. Int J Epidemiol 2007, 36(2):449-457. doi:10.1093/ije/dyl306.

32. BBS/UNICEF: Child and Mother Nutrition Survey 2005. Dhaka: Bangladesh Bureau of Statistics and UNICEF; 2007.

33. Rahman SMM, Kabir I, Khaled MA, Bhuyan MAH, Rashid HA, Malek MA, Khan MR: Prevalence and Determinants of Childhood Obesity in Dhaka City [abstract]. In Proceedings of 10th ASCON. Dhaka; 2002.

34. de Onis M, Blossner M: Prevalence and trends of overweight among preschool children in developing countries. Am J Clin Nutr 2000, 72(4):1032-1039.

35. Rahman SMM, Akter BMD, Siddiqui MZA: Prevalence of childhood Obesity in Dhaka city. Mymensingh Med J 1998, 7(1):3-6.

36. Ferdousi J, Alamgir AKM: Prevalence and Determinants of Overweight in School Students: A Developing Country Perspective [abstract]. Can J Diabetes 2011, 35(2):195.

37. Saraswathi S, Najafi M, Gangadhar MR, Malini SS: Prevalence of childhood obesity in school children from rural and urban areas in Mysore, Karnataka. India. J Life Sci 2011, 3(1):51-55.

38. Sakamoto N, Wansorn S, Tontisirin K, Marui E: A social epidemiologic study of obesity among preschool children in Thailand. Int J Obes Relat Metab Disord 2001, 25(3):389-394. doi:10.1038/sj.ijo.0801477.

39. Weiss R, Caprio S: The metabolic consequences of childhood obesity. Best Pract Res Clin Endocrinol Metab 2005, 19(3):405-419. doi:10.1016/j. beem.2005.04.009.

40. Ebbeling CB, Pawlak DB, Ludwig DS: Childhood obesity: public-health crisis, common sense cure. Lancet 2002, 360(9331):473-482. doi:10.1016/ S0140-6736(02)09678-2 
41. Csabi G, Torok K, Jeges S, Molnar D: Presence of metabolic cardiovascular syndrome in obese children. Eur J Pediatr 2000,

159(1-2):91-94.

42. Pelin A-M, Matasaru S: Metabolic syndrome in obese children and adolescents. Revista medico-chirurgicala a Societatii de Medici si Naturalisti din lasi 2012, 116(4):957-961.

43. Hannon TS, Rao G, Arslanian SA: Childhood obesity and type 2 diabetes mellitus. Am Acad Pediatrics 2005, 116(2):473-480. doi:10.1542/peds.2004-2536.

44. Fagot-Campagna A: Emergence of type 2 diabetes mellitus in children: epidemiological evidence. J Pediatr Endocrinol Metab 2000, 13:1395-1402.

45. Fagot-Campagna A, Pettitt DJ, Engelgau MM, Burrows NR, Geiss LS, Valdez R, Beckles GLA, Saaddine J, Gregg EW, Williamson DF: Type 2 diabetes among North American children and adolescents: an epidemiologic review and a public health perspective. J Pediatr 2000, 136(5):664-672. doi:10.1067/ mpd.2000.105141.

46. Gupta N, Goel K, Shah P, Misra A: Childhood obesity in developing countries: epidemiology, determinants, and prevention. Endocr Rev 2012, 33(1):48-70. doi:10.1210/er.2010-0028.

47. Kelishadi R: Childhood overweight, obesity, and the metabolic syndrome in developing countries. Epidemiol Rev 2007, 29(1):62-76. doi:10.1093/ epirev/mxm003.

doi:10.1186/1471-2458-14-70

Cite this article as: Rahman et al:: Obesity and overweight in

Bangladeshi children and adolescents: a scoping review. BMC Public Health 2014 14:70.

\section{Submit your next manuscript to BioMed Central and take full advantage of:}

- Convenient online submission

- Thorough peer review

- No space constraints or color figure charges

- Immediate publication on acceptance

- Inclusion in PubMed, CAS, Scopus and Google Scholar

- Research which is freely available for redistribution 